$2.0 \mu \mathrm{m}$ wavelength injection seed semiconductor laser for lidar transmitter for global-scale measurements of $\mathrm{CO}_{2}$

Siamak Forouhar

\&

Ryan Briggs, Mahmood Bagheri, Clifford Frez; Mathieu Fradet

Jet Propulsion Laboratory, California Institute of Technology

- Introduction

Outline

- Global CO2 measurement via LIDAR

- Laterally coupled distributed-feedback (LC-DFB) lasers@ $2 \mu \mathrm{m}$ wavelength

- Summary 
Spatial and temporal mapping of $\mathrm{CO}_{2}$ is important for understanding natural carbon cycles, climate change, and human environmental impact

\section{Ground-based networks}

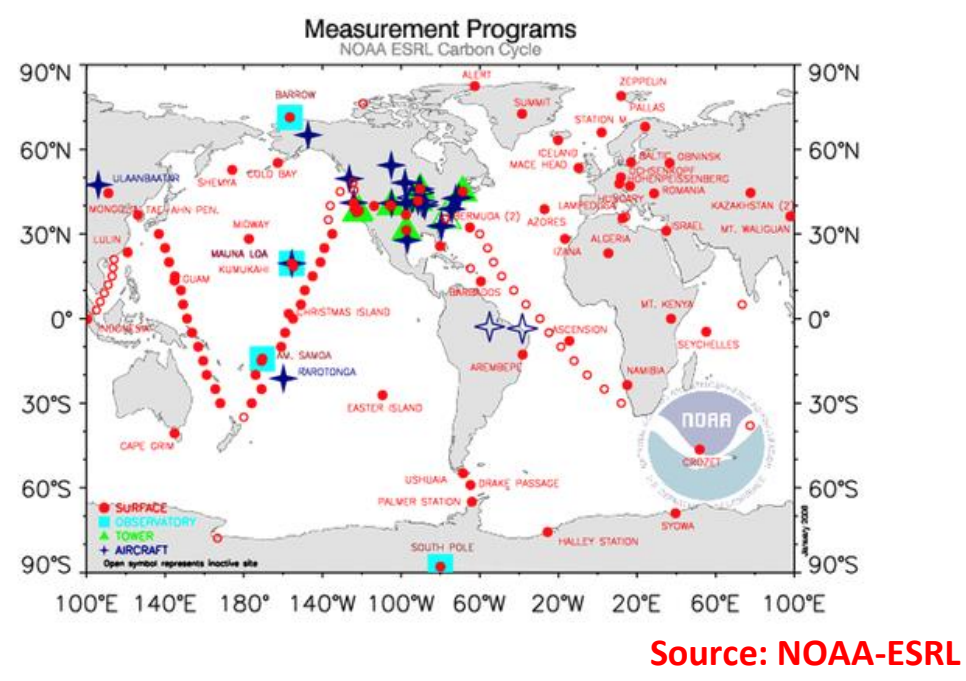

Longest $\mathrm{CO}_{2}$ measurement (continuous since 1957)

$>$ Observation from surface $\sim 500 \mathrm{~m}$

D High temporal resolution, accuracy and precision

$>$ Point measurements, sparse coverage

\section{Air-craft Campaigns}

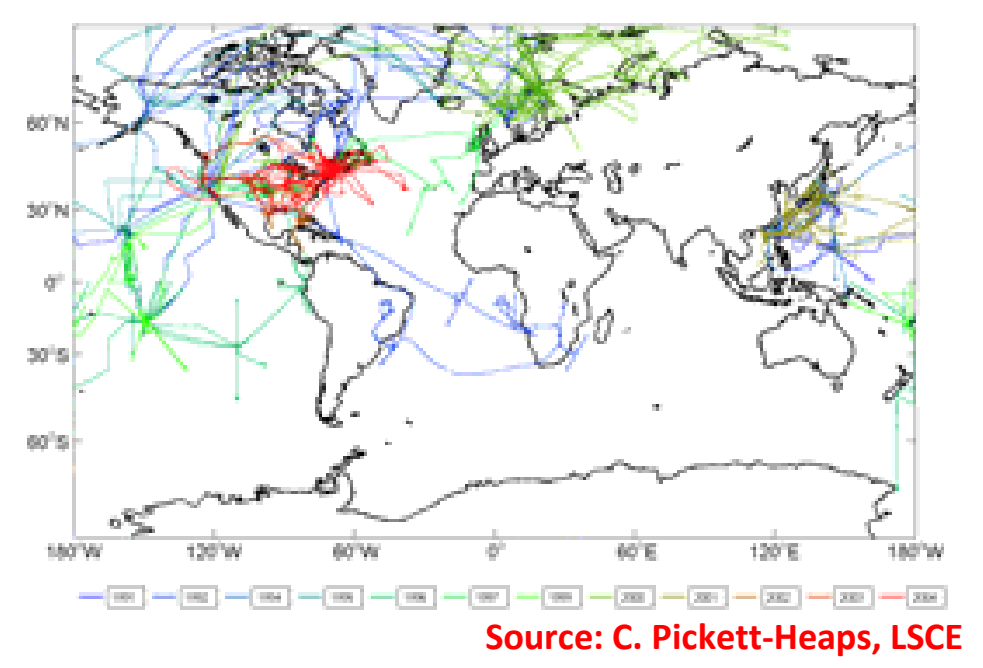

Varying altitudes accessible

$>$ Vertical profiles

$>$ High accuracy and precision

$>$ Infrequent flights/ operations

$>$ Regional measurements 
CO2 LIDARS are being developed by NASA and ESA

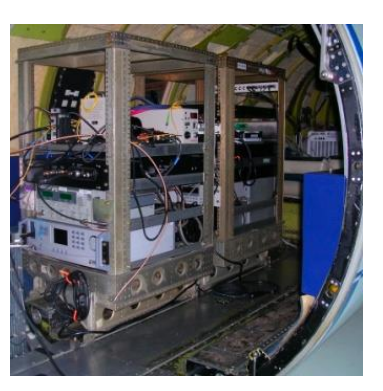

CO2 DIAL- Lear Jet NASA GSFC (2008- present) $1.5 \mu \mathrm{m}$ Fiber Laser

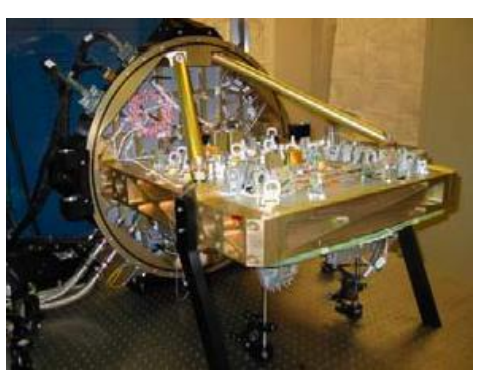

CO2 Absorption SpectrometerJPL(2006 - present) 2 um CW Laser

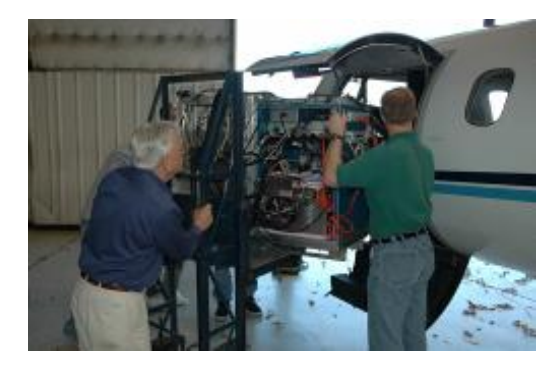

CO2 DIAL-King Air / Lear Jet NASA LaRC $1.5 \mu \mathrm{m}$ Fiber Laser
A-SCOPE lidar concept

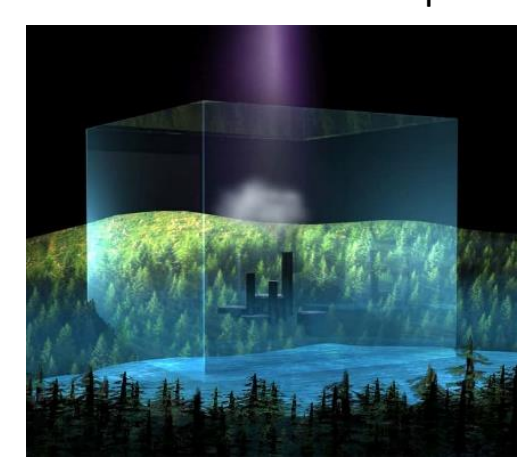

ESA- $2 \mu \mathrm{m}$ DIAL
Common features:

Transmitter

- frequency stable

- high spectral purity

- high power or energy

\section{Differences:}

Transmitter:

- wavelength either $1.57 \mu \mathrm{m}$ or $2.05 \mu \mathrm{m}$

- pulsed or CW

- two or three or more laser system

Receiver

- heterodyne or direct detection

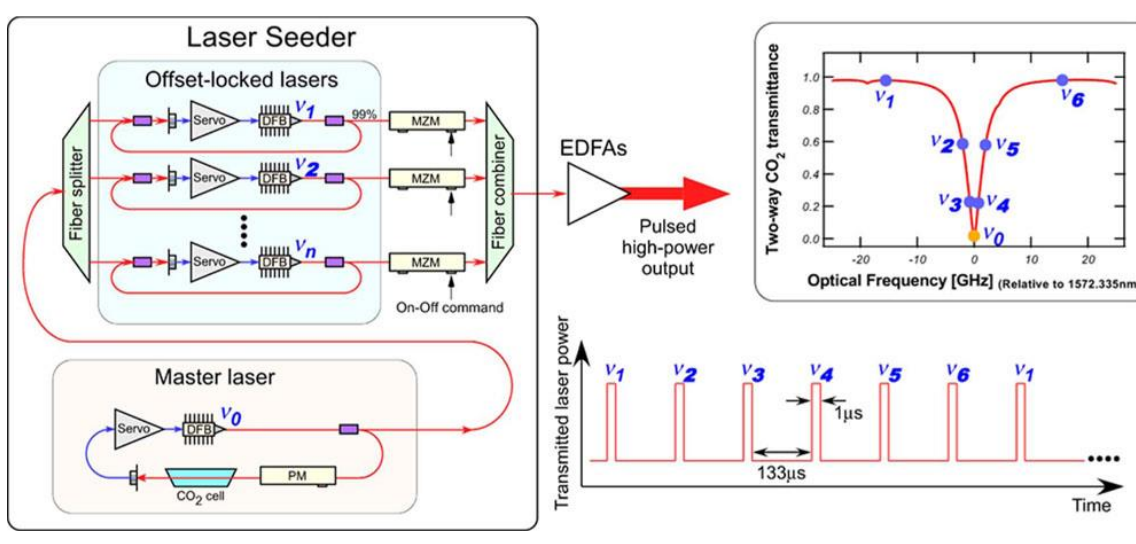

K. Numata, J.R. Chen, S.T. Wu, J.B. Abshire, M.A. Krainak, Appl. Opt. 50, 1047 (2011) NASA/Goddard

- high sensitivity and low noise

- high bandwidth readout 


\section{JPL LAS instrument is at $2.05 \mu \mathrm{m} \mathrm{CO} 2$ absorption band}

for reason of strong $\mathrm{CO}_{2}$ absorption and minimal sensitivity to variations in temperature and water vapor concentration

Components and required specs:

- Airborne transmitter

$$
\text { - } \lambda \quad \text {->2.05097 } \mu \mathrm{m}, \mathrm{R}(30) \text { line }
$$

center

- power $\quad \rightarrow 180 \mathrm{~mW}$

- linewidth $<200 \mathrm{KHz}$ in $0.5 \mathrm{msec}$

- Frequency stability $2 \mathrm{MHz}$

- tunable over $12 \mathrm{GHz}$

- Injection seed

- $\lambda \quad->2.05097 \mu \mathrm{m}, \mathrm{R}(30)$ line

center

- power $\quad->10 \mathrm{~mW}$

- linewidth <200KHz in $0.5 \mathrm{msec}$

- Frequency stability $1 \mathrm{MHz}$

- Local oscillator
- $\lambda \quad->2.05097 \mu \mathrm{m}$
- power $\quad \rightarrow 50 \mathrm{~mW}$
- linewidth $<200 \mathrm{KHz}$ in $0.5 \mathrm{msec}$
- Frequency stability $1 \mathrm{MHz}$

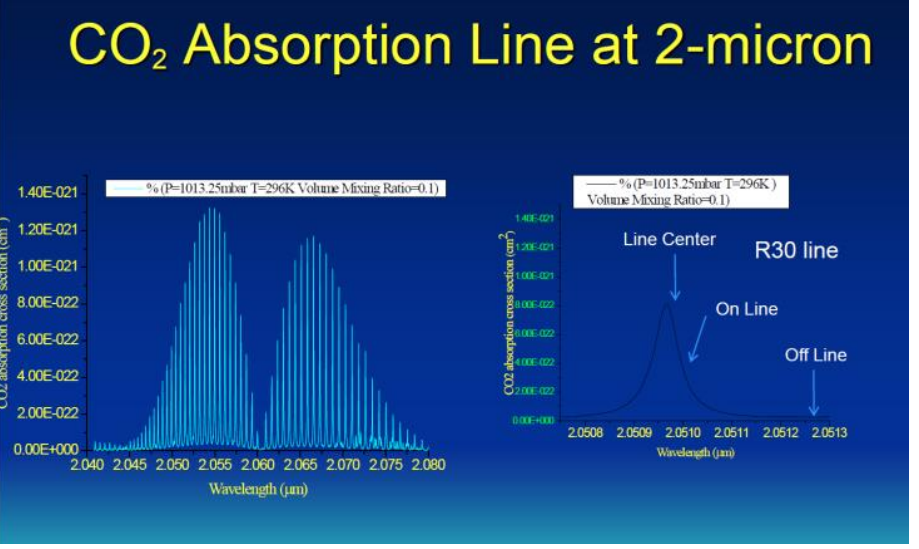

Semiconductor seed laser

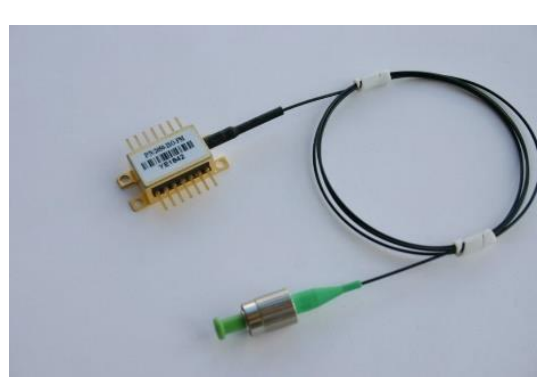

Fiber laser and amplifier

- Laser amplifier (or fiber amplifier for modulated CW system)

- Detectors with high gain low noise for direct detection

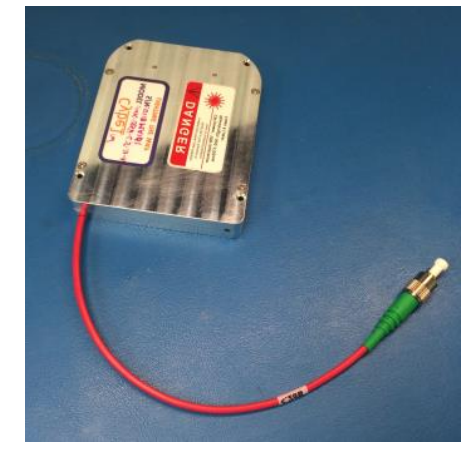

LiNbO3 modulators

- Detectors with high quantum efficiency, high bandwidth for heterodyne detection

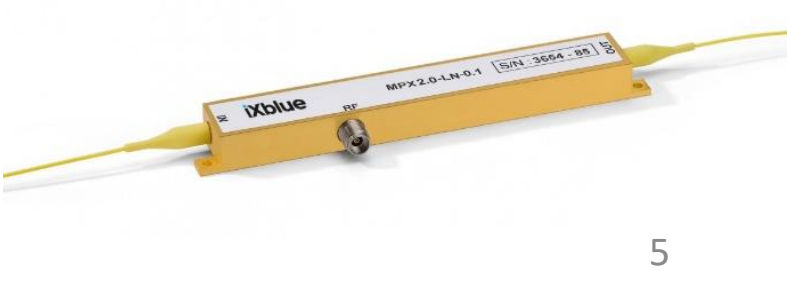




\section{LAsA Optimum DFB laser power for Thulium Doped Fiber Amplifier at $2.050 \mu \mathrm{m}$}

Input power level of $2 \mathrm{~mW}$ is sufficient for a Thulium Doped Fiber Amplifier (TDFA) working at $2050 \mathrm{~nm}$.

To get $500 \mathrm{~mW}$, we will need to use two stages as follows.

Preliminary simulations for 2052nm Tm amplifier and effect of input power Note that for each configuration the pump powers where selected to generate $+27 \mathrm{dBm}$ output power for $0 \mathrm{dBm}$ input and held constant for all other input powers.

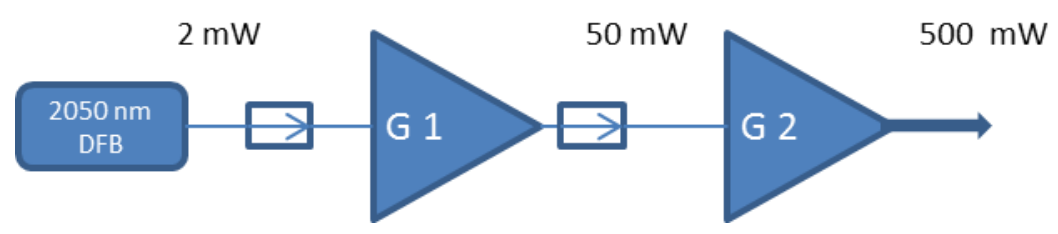

To get $10 \mathrm{~W}$, we can add a third stage.
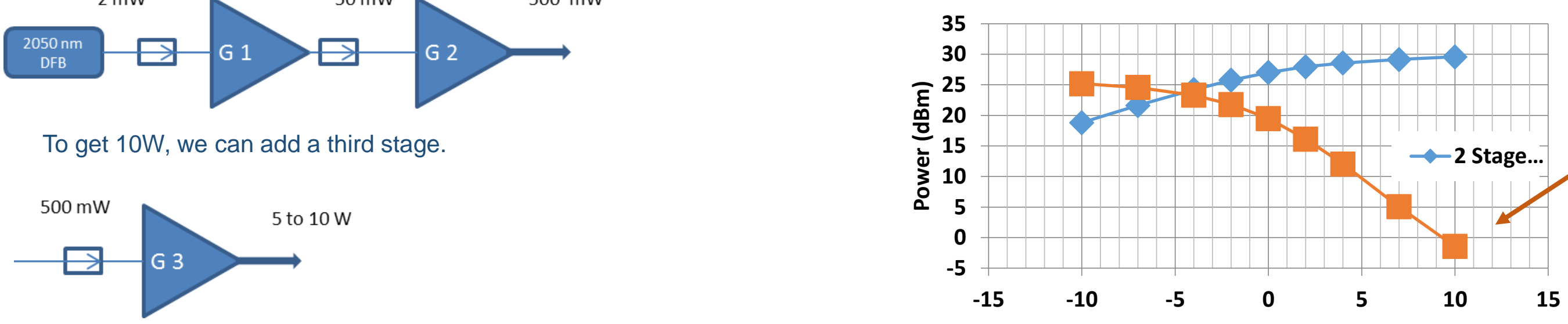

If we have a $20 \mathrm{~mW}$ from the DFB laser, we can get $500 \mathrm{~mW}$ with a single stage and $10 \mathrm{~W}$ with a dual stage.

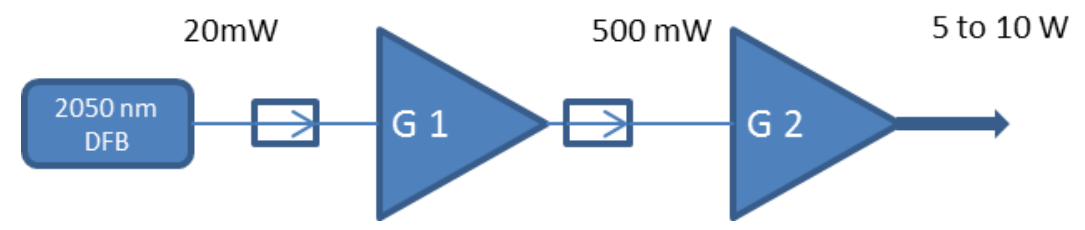

Note that if we use $40 \mathrm{~mW}$ as the input instead of $20 \mathrm{~mW}$, we can use a single stage to get $500 \mathrm{~mW}$, but the output will have an improved

SNR (by $\sim 3 \mathrm{~dB}$, assuming that the noise figure, NF, remains unchanged).

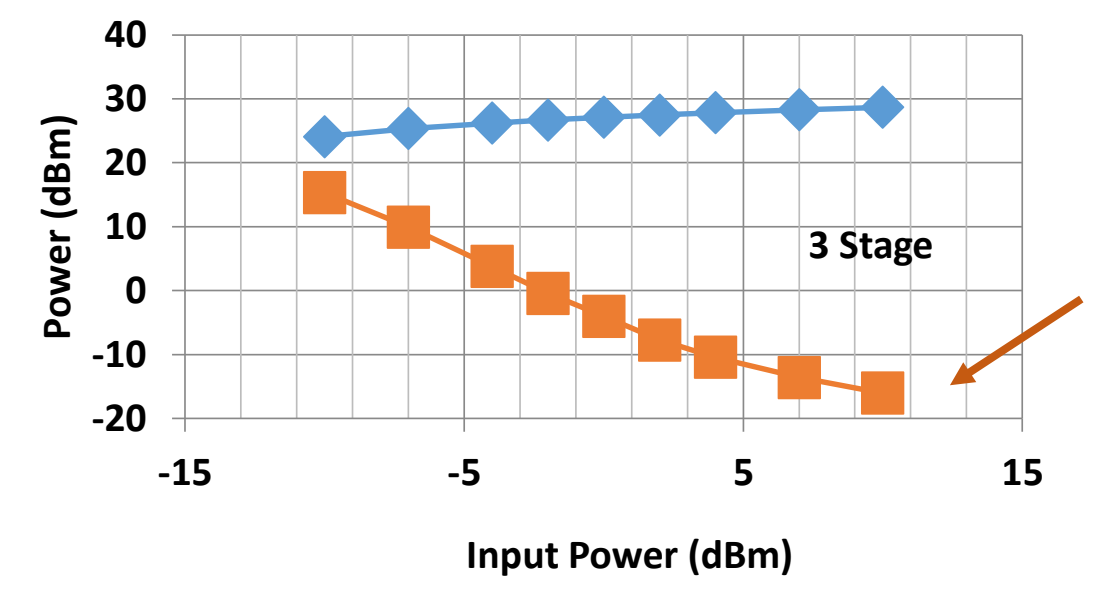




\section{Current technology:}

Diode pumped solid-state crystal lasers each in a cavity that comprises several optical elements and a piezo-electric transducer

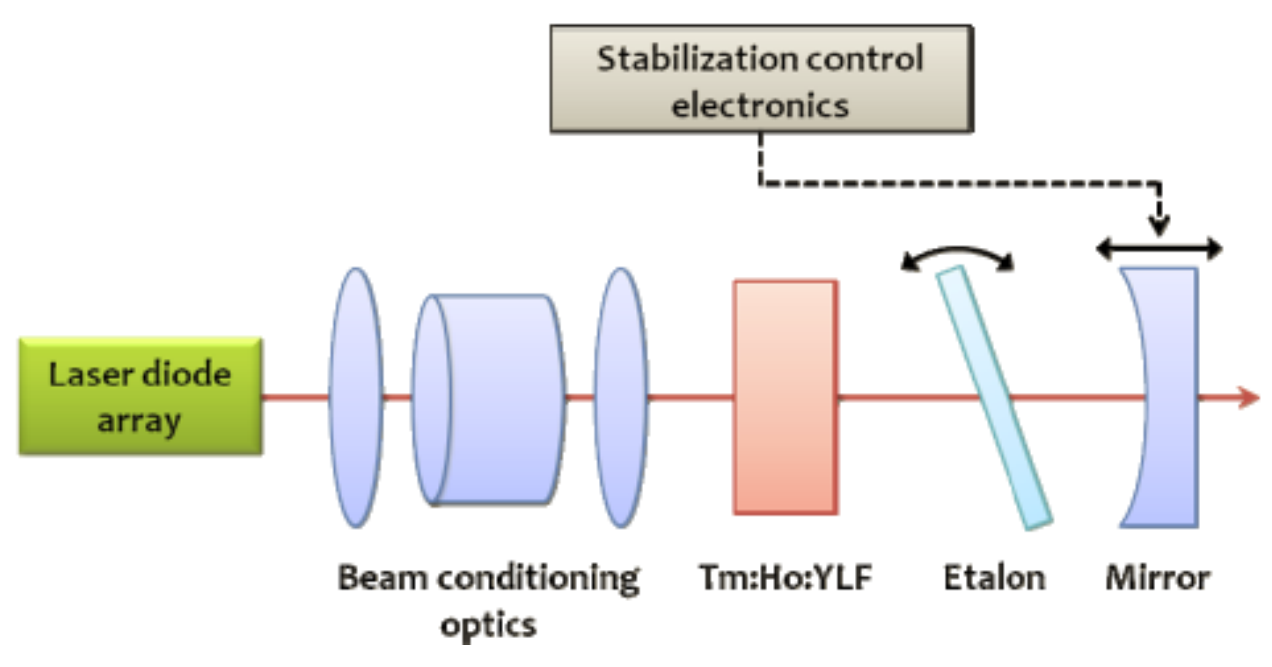

Alternative approach:

- Replace the diode pumped solid-state-laser with monolithic diode lasers at $2 \mu \mathrm{m}$

- Depending on the performance: Potential replacement for injection seed, master oscillator, reference oscillator, air borne transmitter, and local oscillator

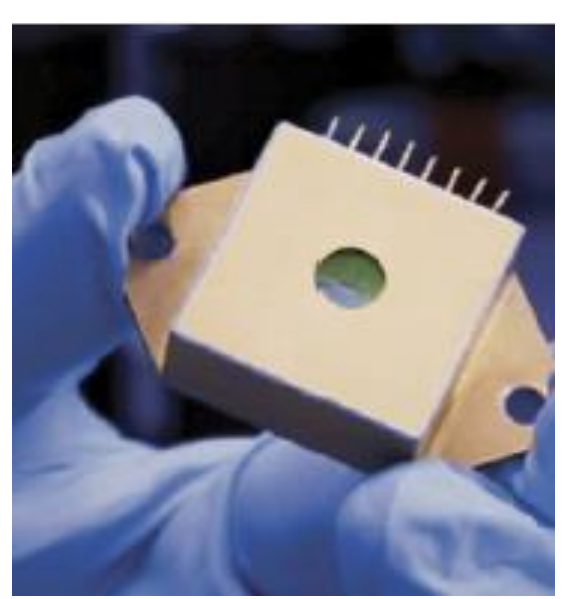



lasers

- Laser material systems for 2- $\mu \mathrm{m}$ emission:

- Strained InGaAs QWs on InP: Power limited by Auger recombination and poor carrier confinement

- GaSb-based structures: Regrowth difficult (esp. on Al-containing layers) - prevents buried grating fabrication

- DFB lasers can be realized with AIGaAsSb/InGaSb lasers using laterally coupled gratings:

- GaSb-based LC-DFB lasers with etched gratings should exhibit lower loss and higher power

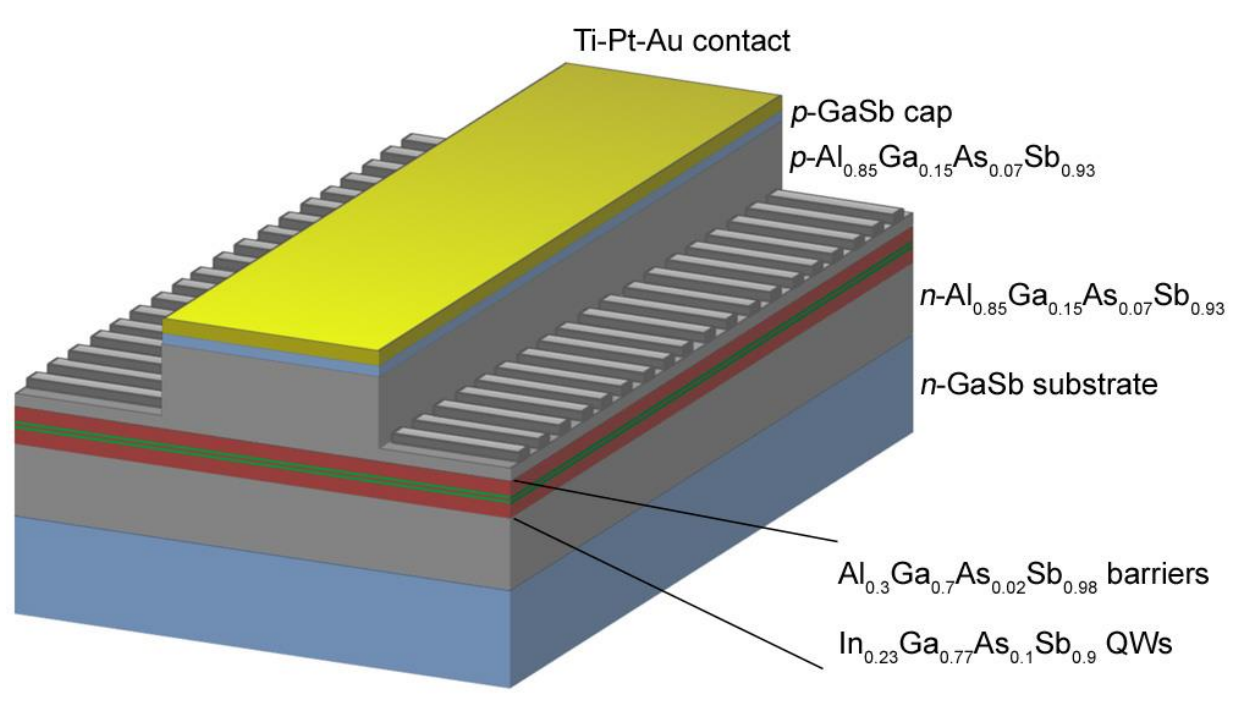




\section{Laterally Coupled DFB laser fabrication}

Laterally coupled etched diffraction gratings
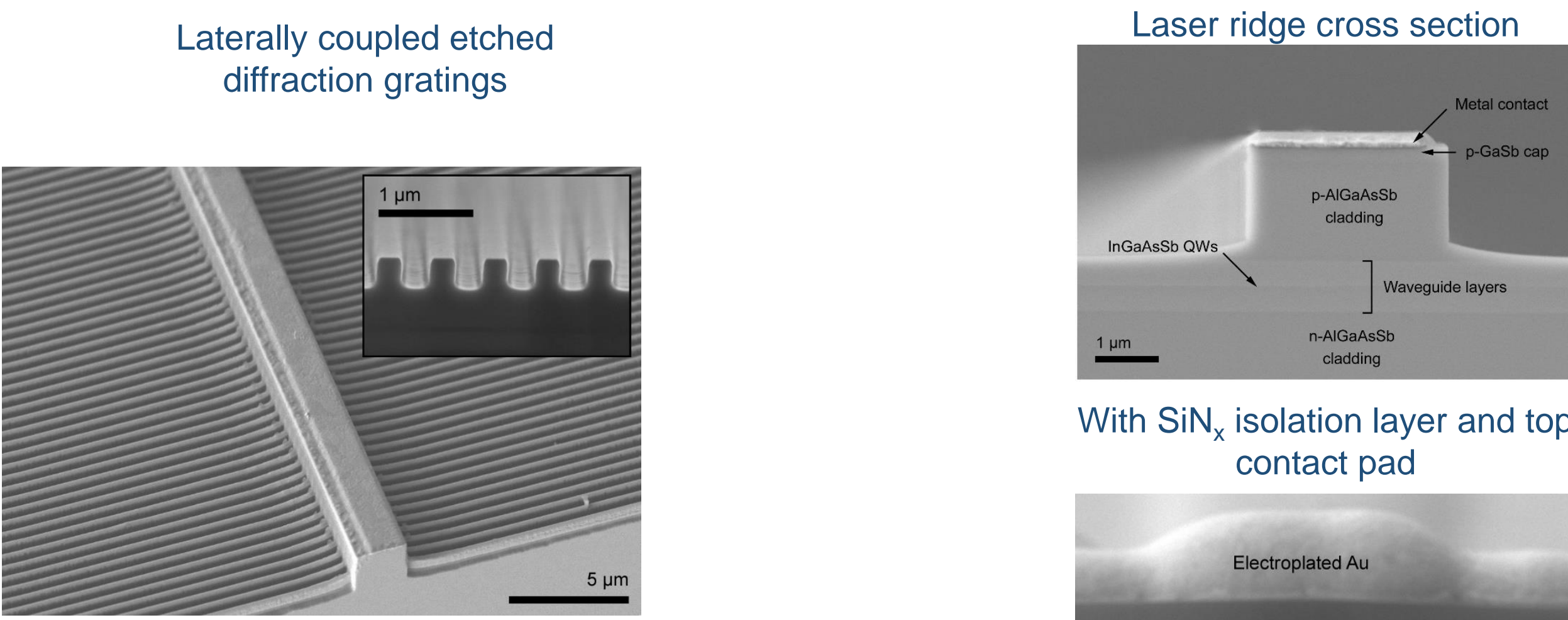

With $\mathrm{SiN}_{\mathrm{x}}$ isolation layer and top contact pad

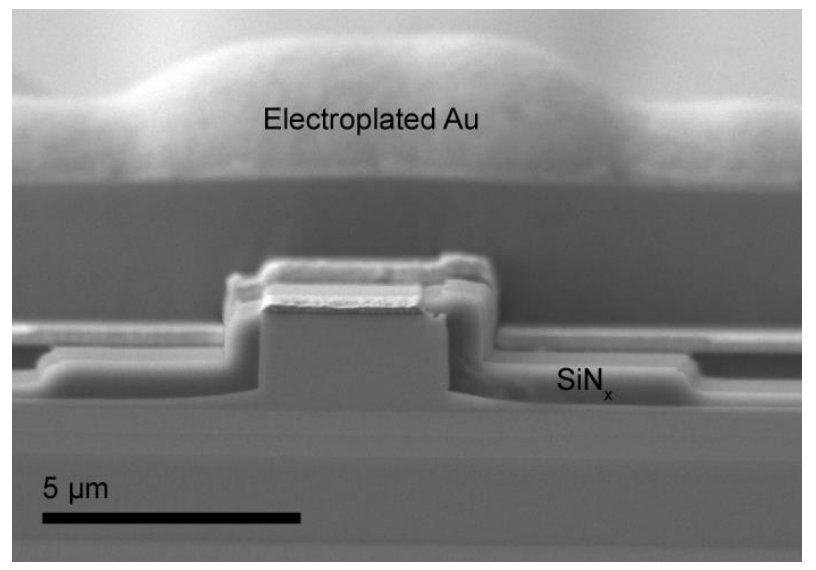

- Second-order gratings etched alongside ridges

- $\mathrm{SiN}_{x}$ isolation layer deposited by PECVD, followed by electroplating of thick Au top contacts

S. Forouhar, R.M. Briggs, C. Frez, K.J. Franz, A. Ksendzov, APL 100, 031107 (2012) 


\section{Facet coating and die mounting}

- Facet coatings:

- Emission facet (AR): 0.2 - 2\% reflectivity

- Back facet (passivated): $30 \%$ reflectivity

- Provides best balance between power and tuning stability

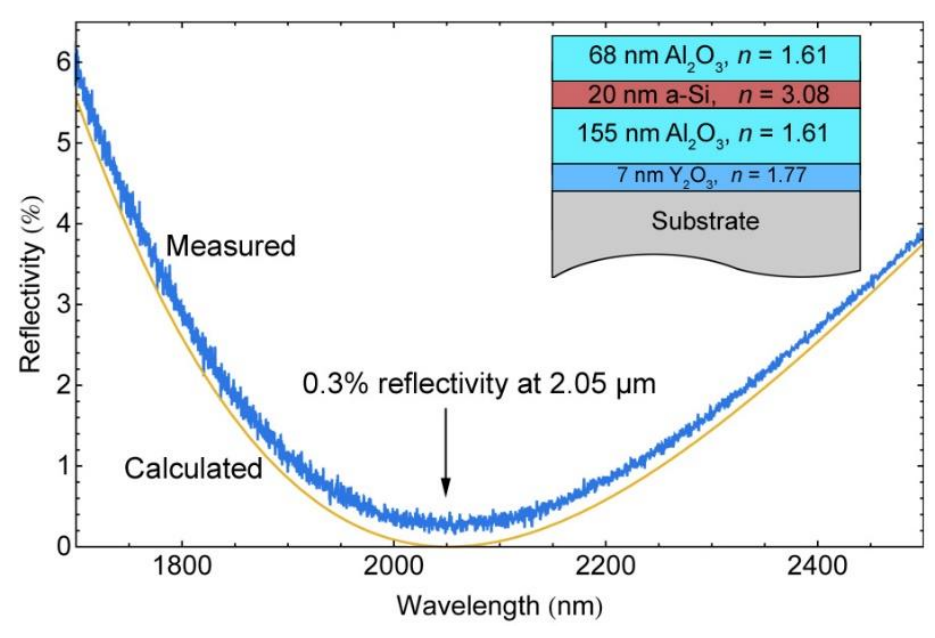

- Cleaved individual laser diodes are bonded and wired to compact sub-mounts:

- Die bonding process uses $\mathrm{Au}_{0.1} \mathrm{Sn}_{0.9}$ solder at 260 ${ }^{\circ} \mathrm{C}$

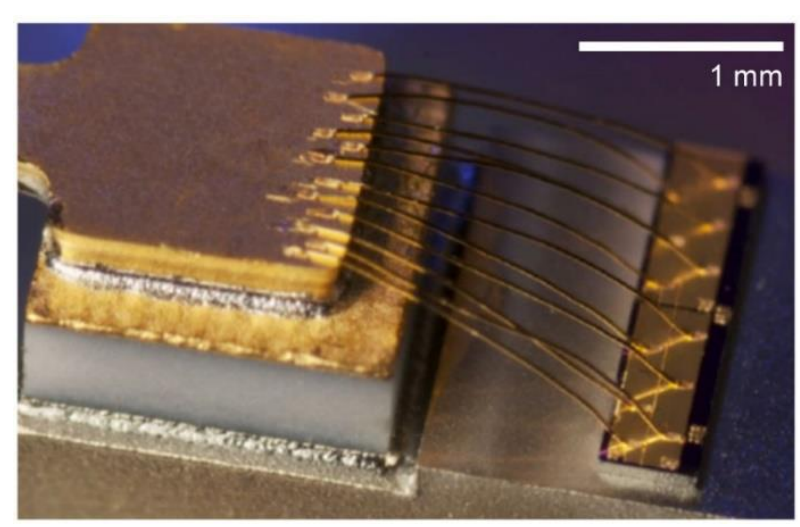

- Au-coated sub-mounts compatible with sealed TE-cooled packages 


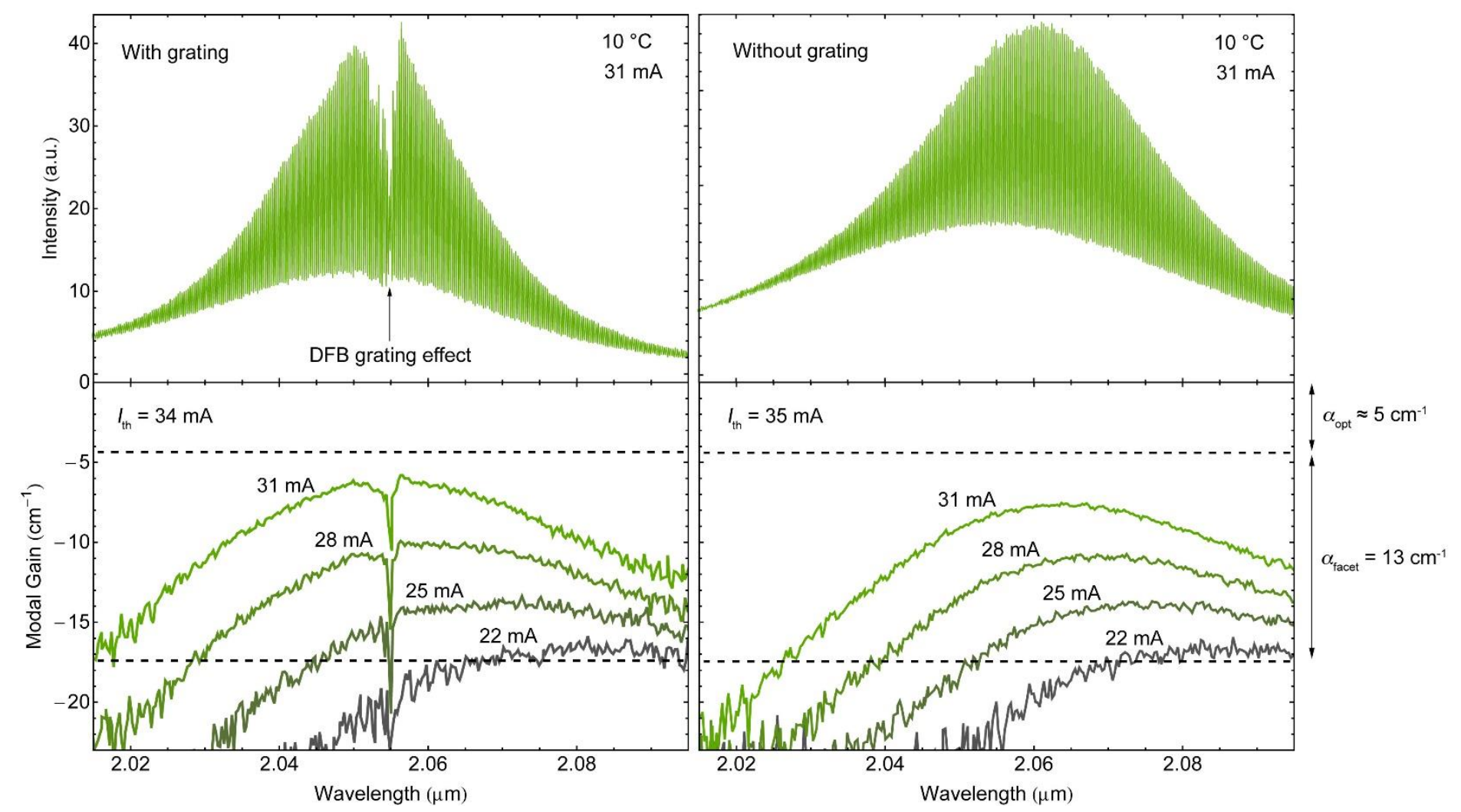

- Grating effect is clearly visible in sub-threshold electroluminescence spectra

- No observed increase in waveguide loss away from Bragg wavelength compared with Fabry-Perot lasers 


\section{2- $\mu \mathrm{m}$ LC-DFB laser performance}

\section{Light-current-voltage performance}
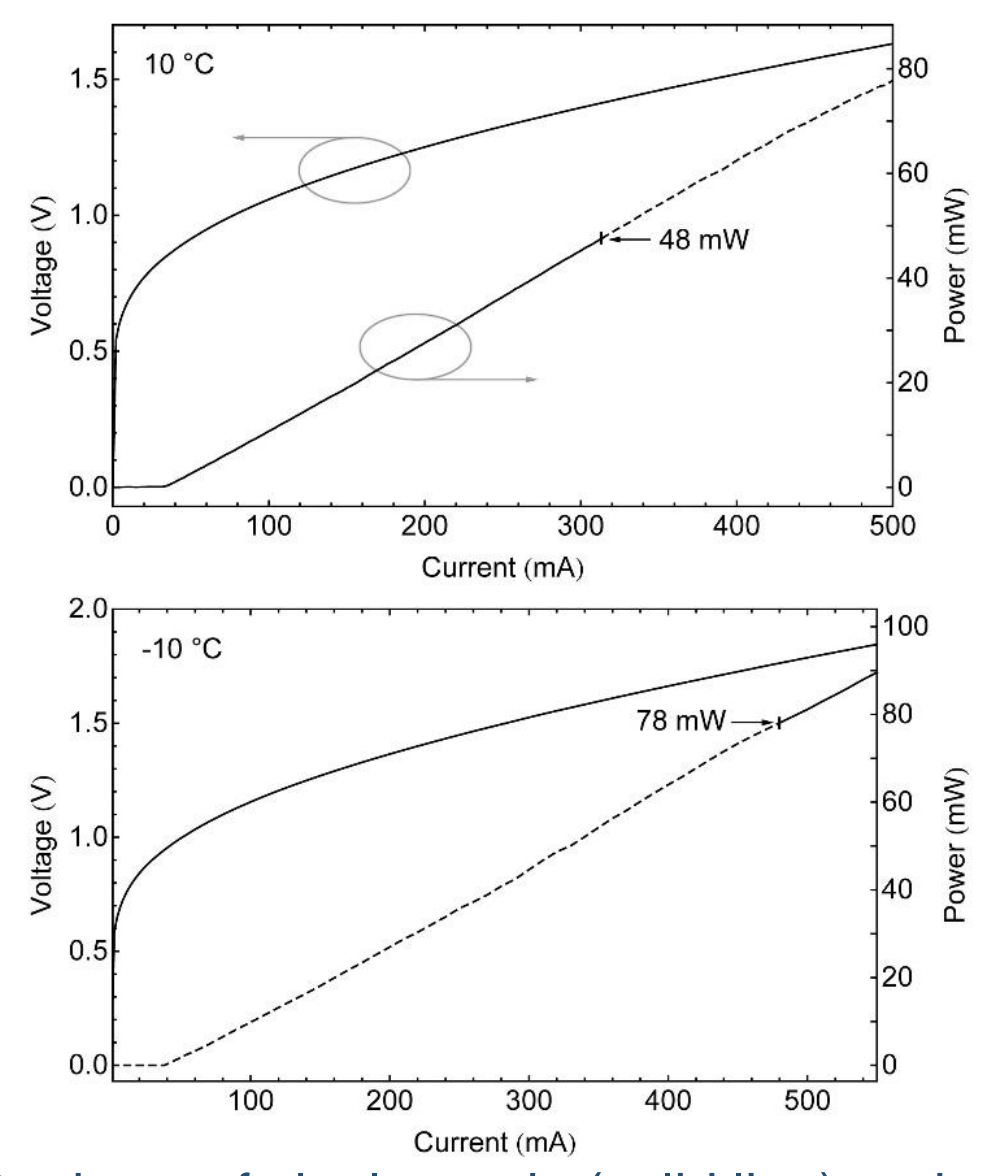

- Regimes of single-mode (solid line) and multimode (dashed line) emission are observed

- Single-mode output exceeds $80 \mathrm{~mW}$ at $-10^{\circ} \mathrm{C}$
Laser emission spectra vs. current

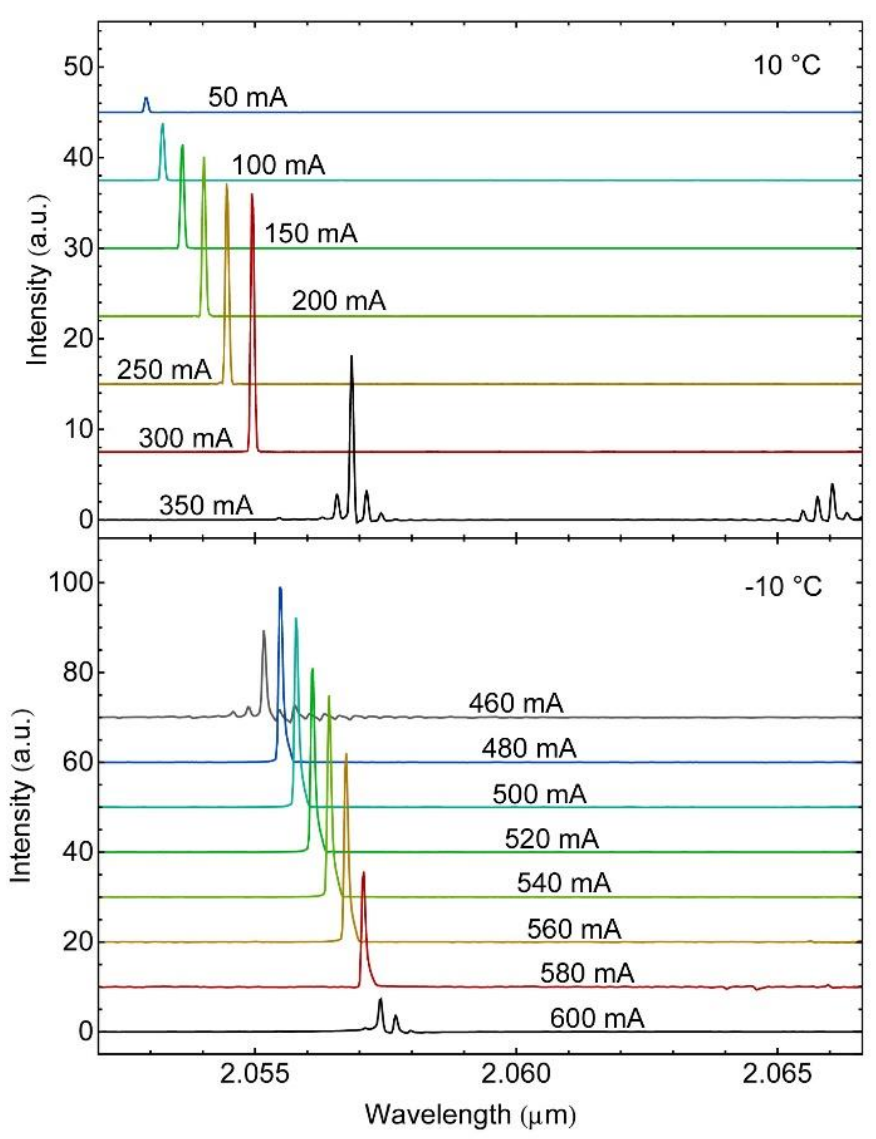

- DFB emission wavelength tunes continuously with increasing current (or temperature)

- Thermal tuning rate is $0.20 \mathrm{~nm} / \mathrm{C}$ 


\section{2- $-\mu \mathrm{m}$ LC-DFB laser performance}

Thermal tuning of gain spectrum
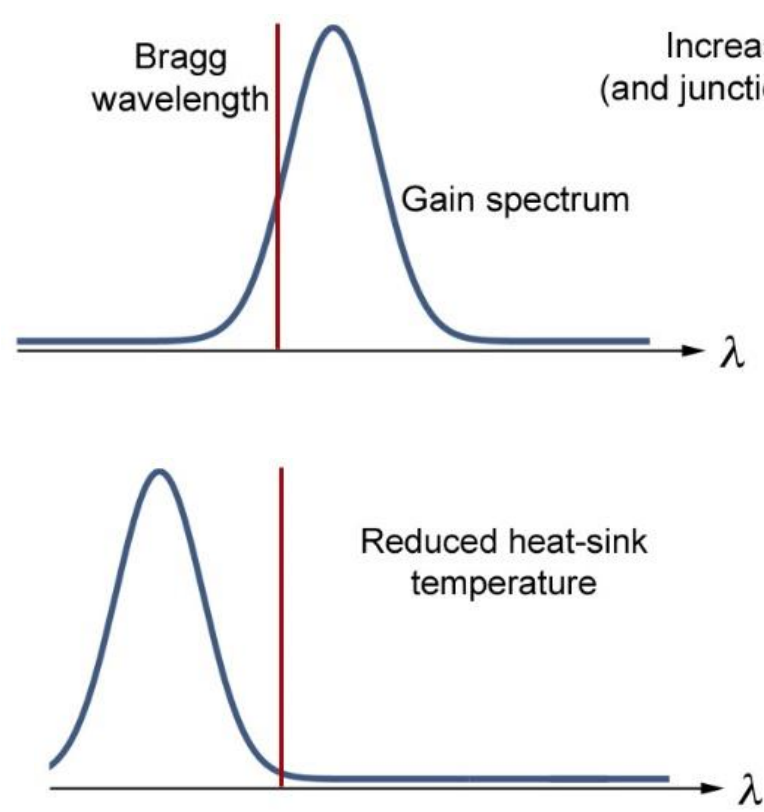

creasing current
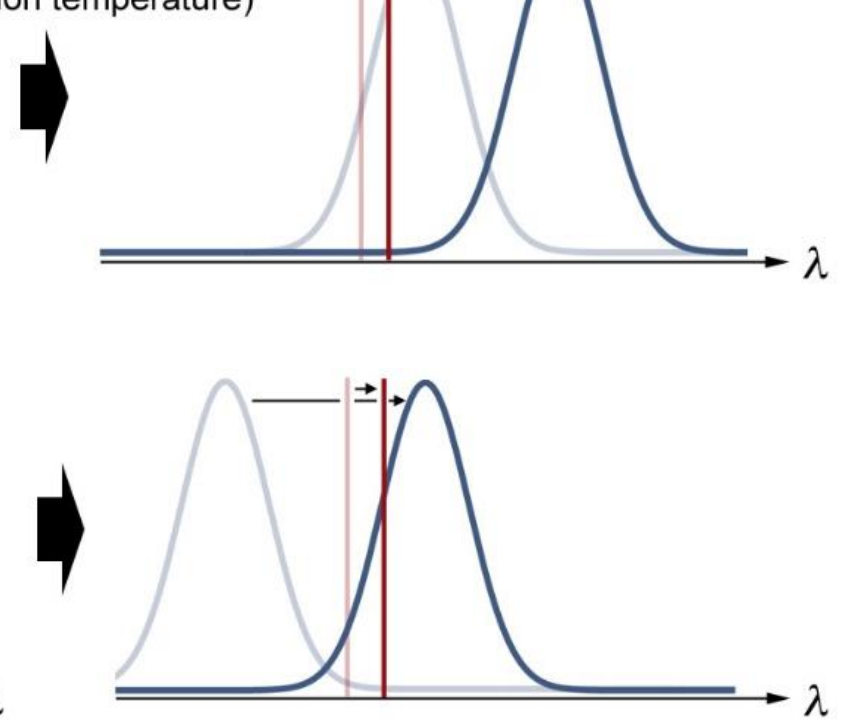

Laser emission spectra vs. current

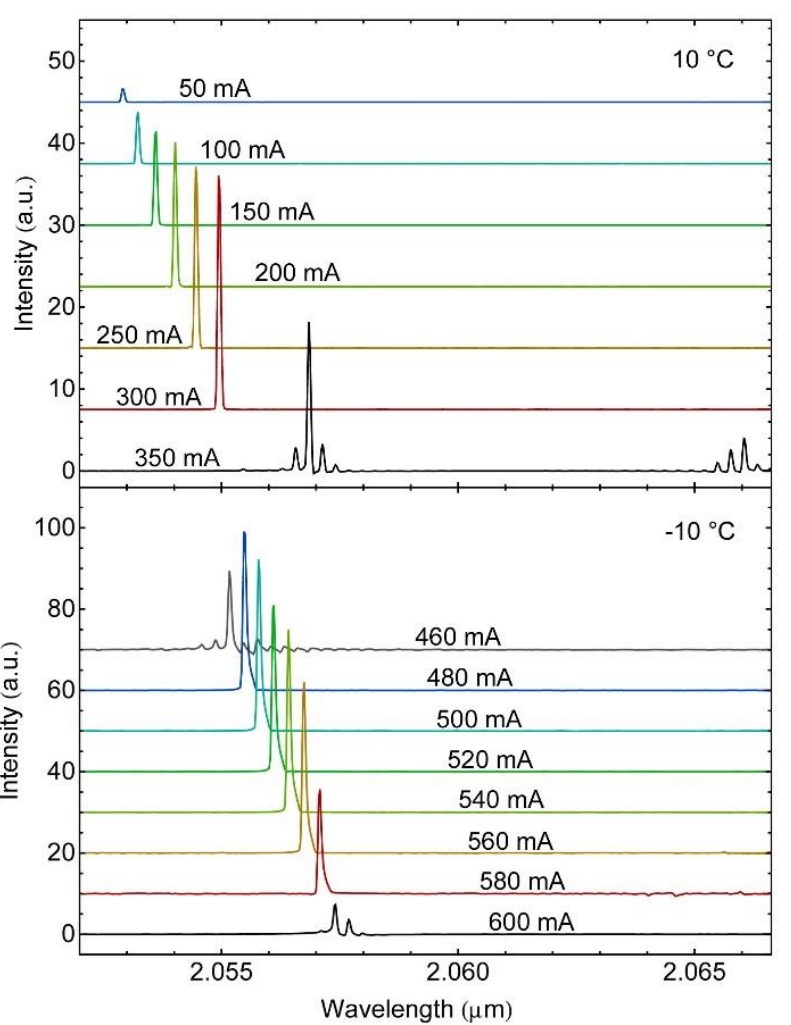

- Single-mode operation corresponds to the Bragg wavelength overlapping the gain spectrum

- Thermal tuning of the gain spectrum is an order of magnitude more severe than DFB tuning $\left(>2 \mathrm{~nm} /{ }^{\circ} \mathrm{C}\right)$ 
Design of a laser package with optical components for operation in $2 \mu \mathrm{m}$ wavelength

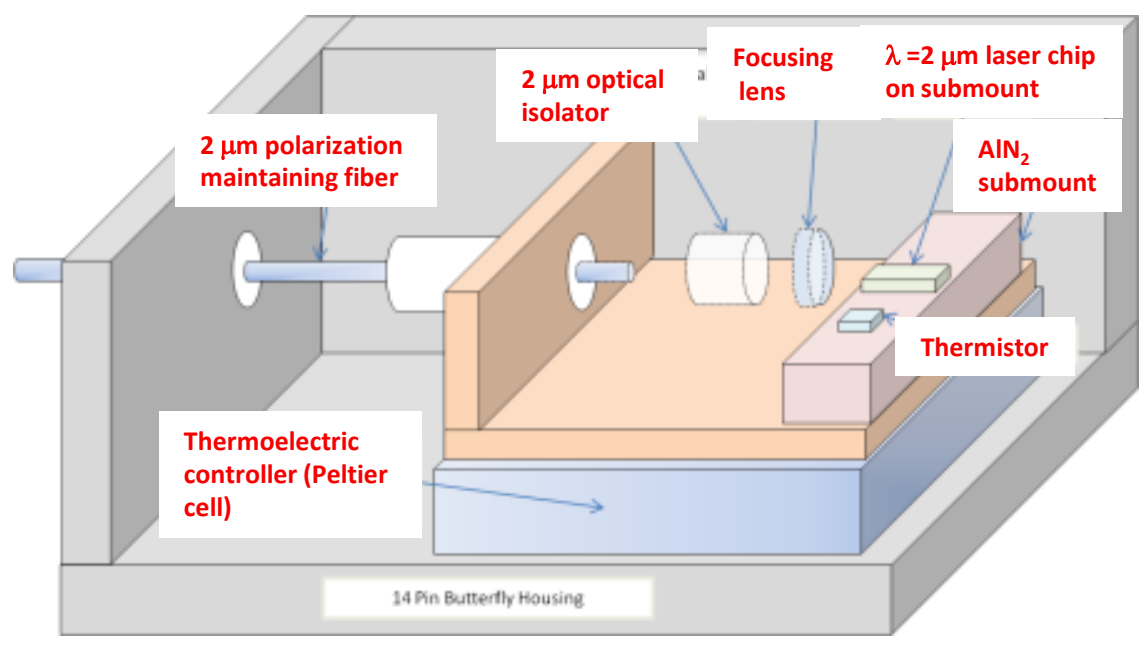

Courtesy of Eblana Photonics, Ltd.

Schematic of a laser package with crossed cylinder optical lens
Calculated laser farfield pattern for our current structure (left) and optimized structure (right)

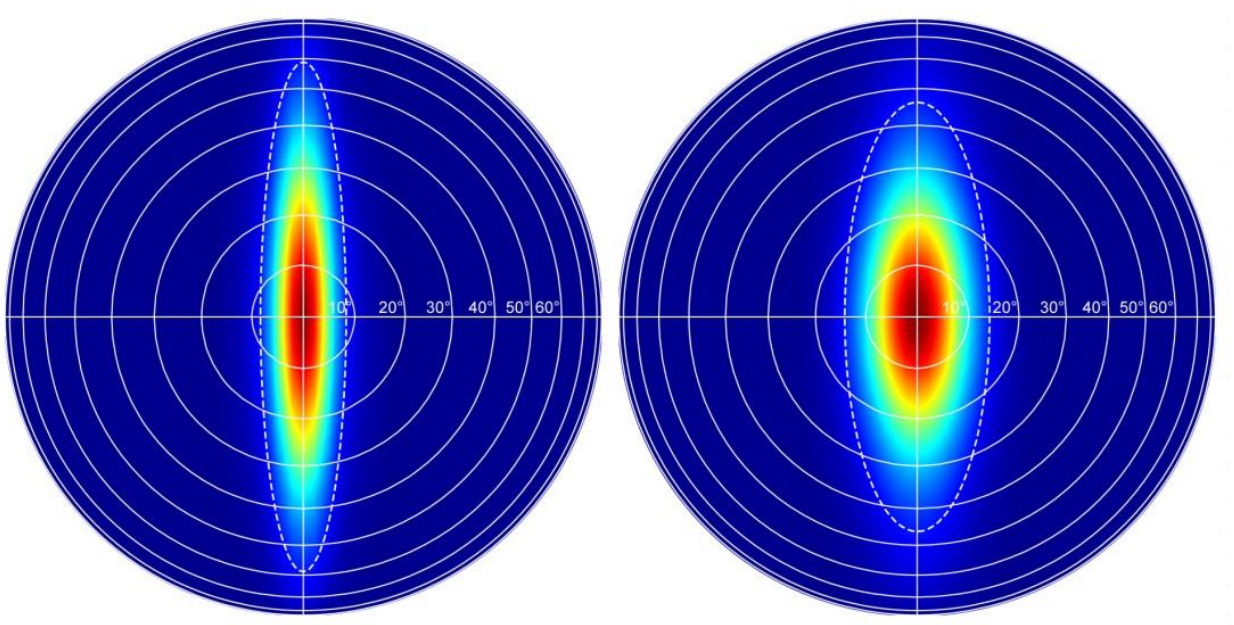

Optical fiber mode profile

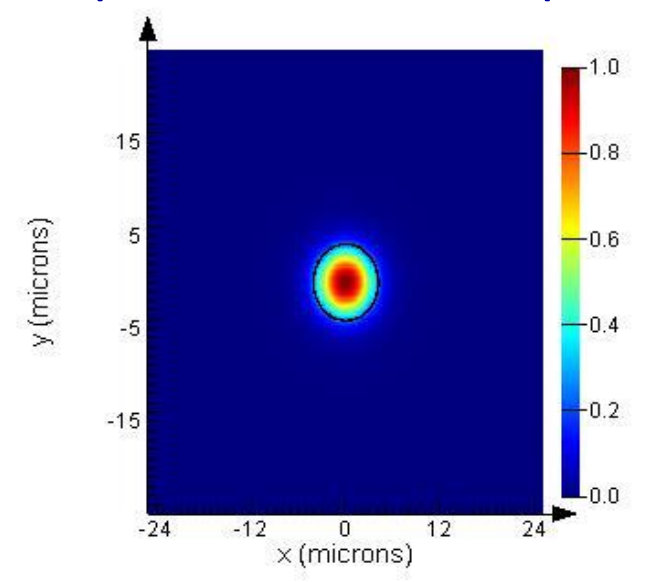




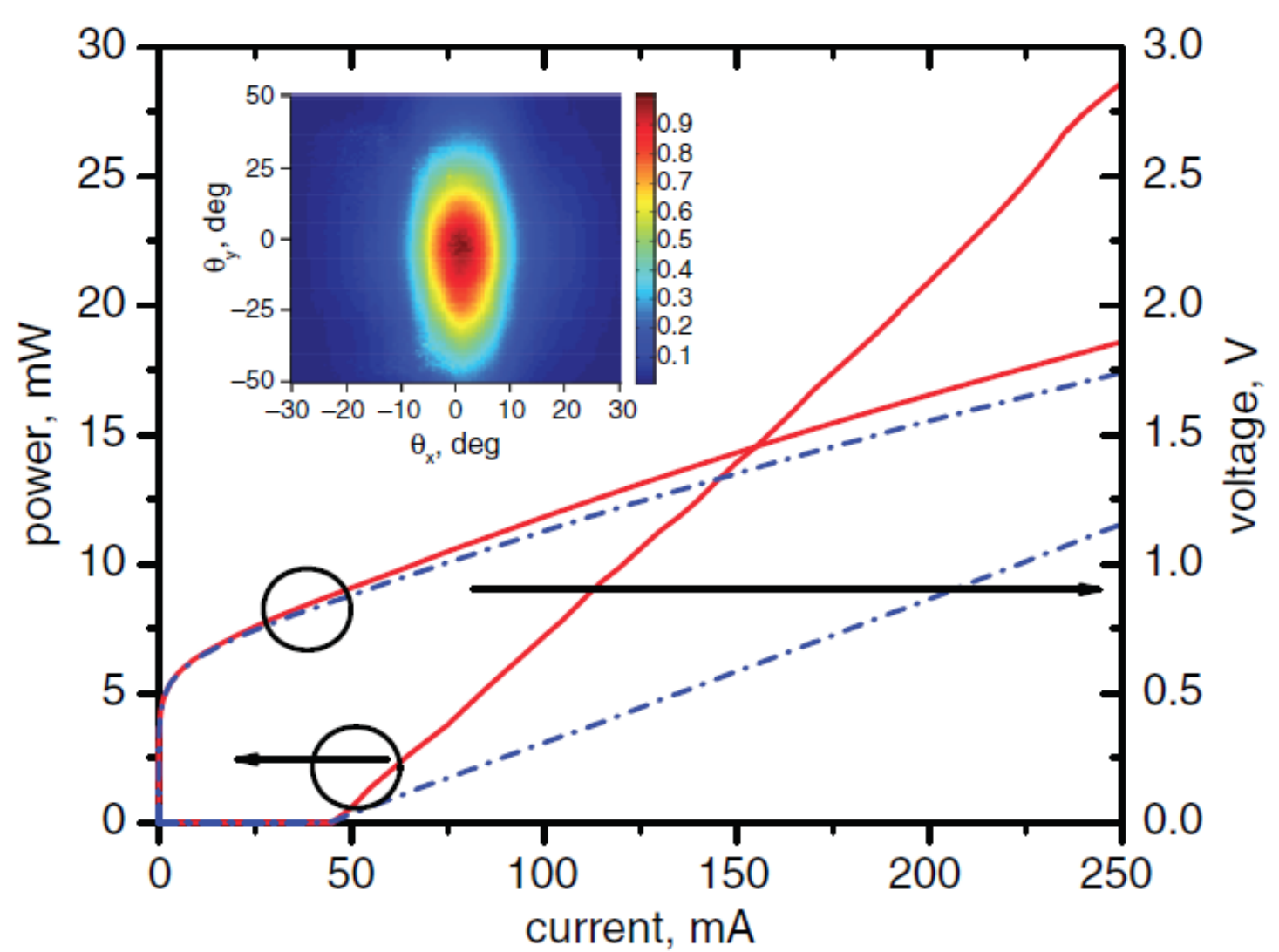

Fig. 2 Left axis shows CW output power collected from laser diode's emitting facet (solid line) before packaging assembly and optical power collected from end of optical fibre (dashed line); right axis shows corresponding voltage across diode PN junction

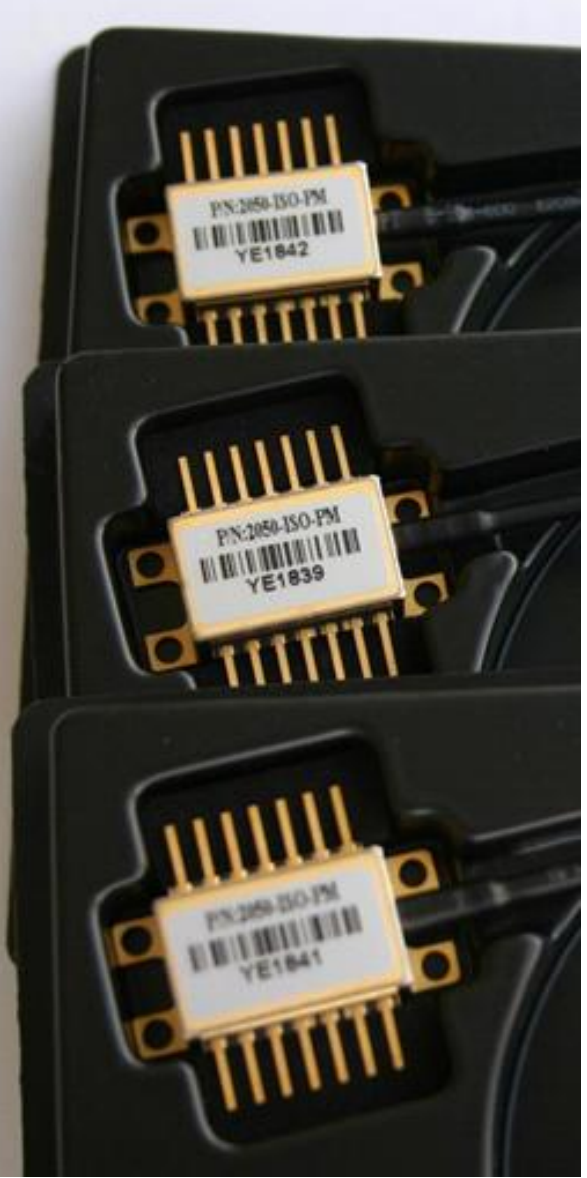


(a)

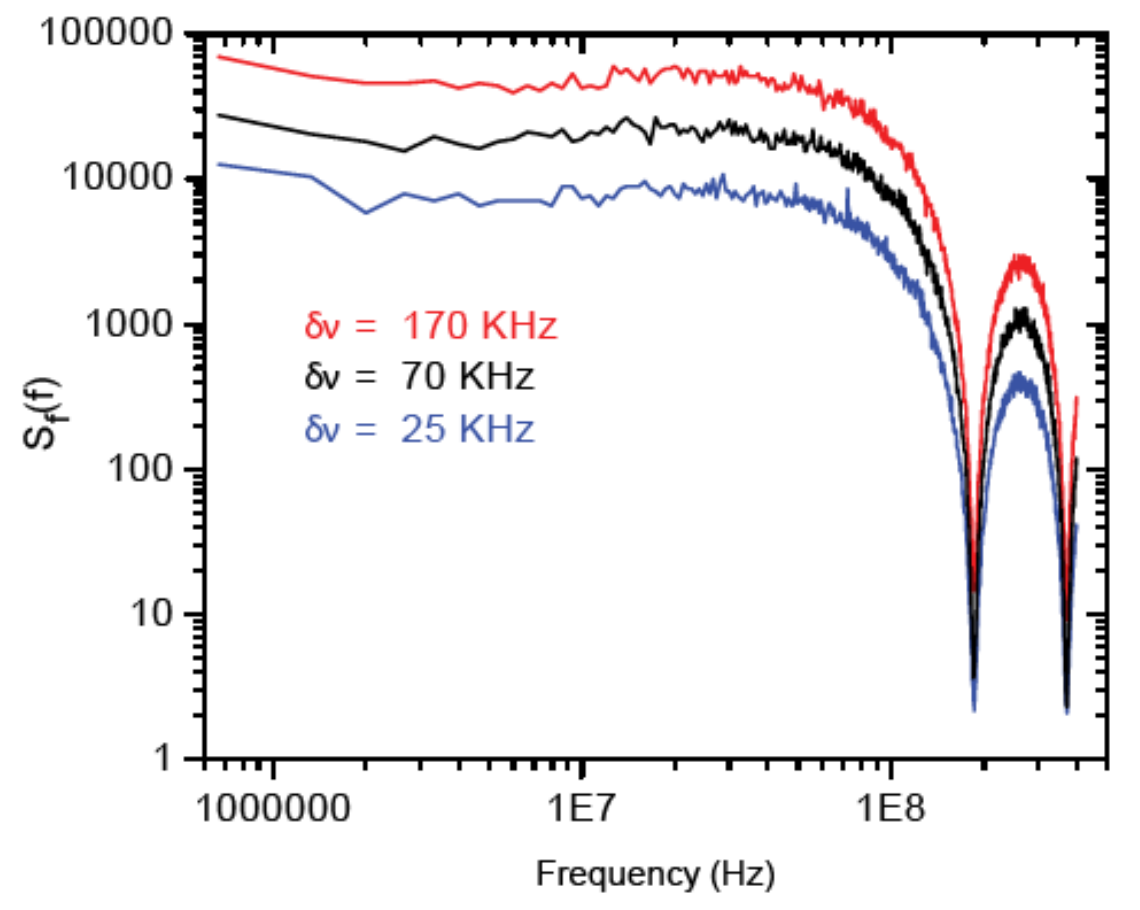

(b)

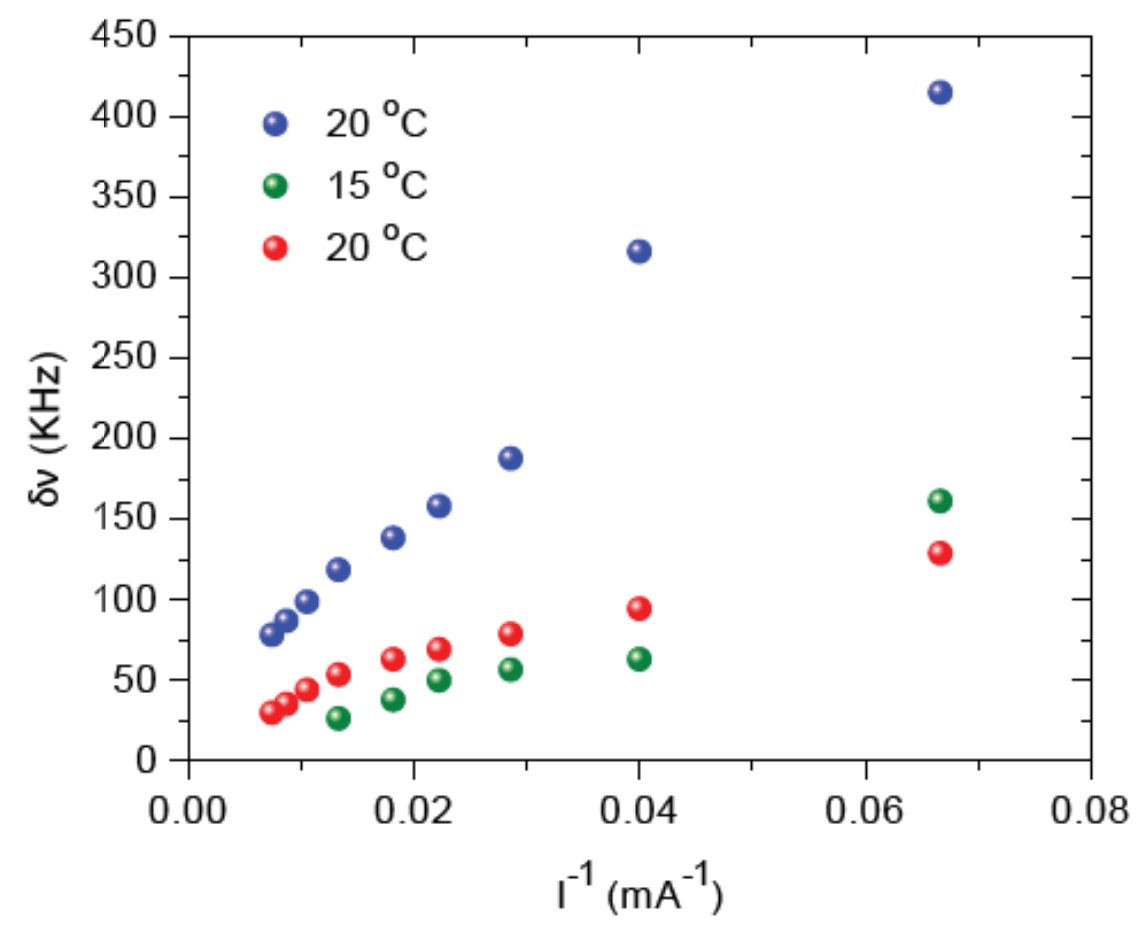

(a) Phase noise spectra of the laser measured at different currents showing unambiguous interpretation of laser linewidth.

(b) Extracted laser linewidth measured as a function of its output power at three different heat sink tempaeratures showing better than $\mathbf{5 0}$ $\mathrm{KHz}$ laser linedith at more than $15 \mathrm{~mW}$ output power. 


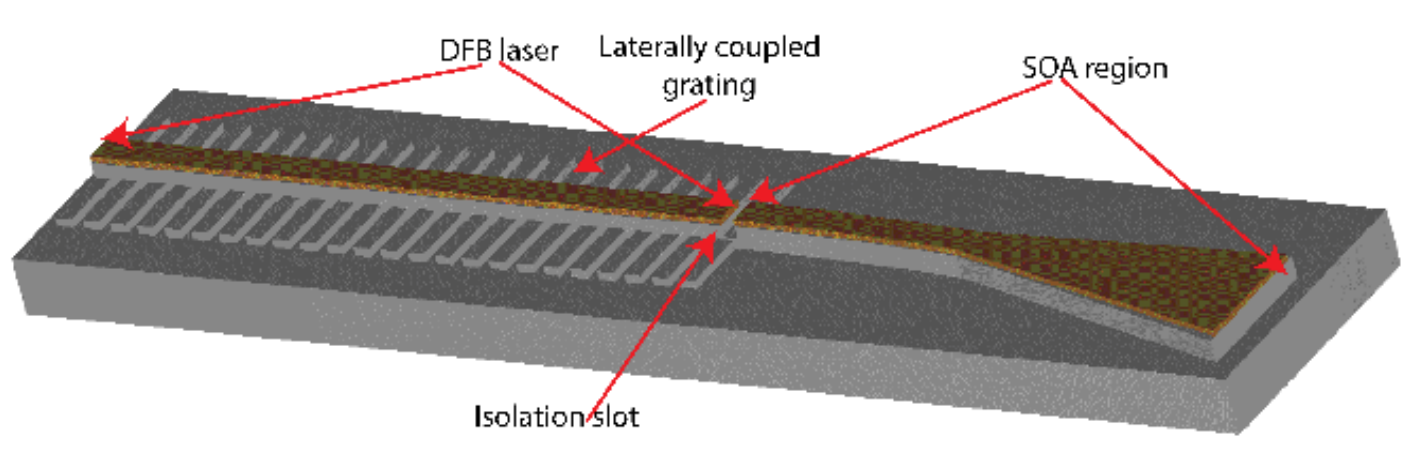

Monolithic Laser Amplifier at $2 \mu \mathrm{m}$ 
- 2- $\mu \mathrm{m}$ LC-DFB laser performance:

- Continuous tuning near $2.05 \mu \mathrm{m}$ wavelength

- Single-mode output (AR-coated facet): $>40 \mathrm{~mW}$ at $10^{\circ} \mathrm{C}$ and $>80 \mathrm{~mW}$ at $-10{ }^{\circ} \mathrm{C}$

- Measured linewidth: $<200$ kHz (limited by environmental noise)

- Lasers are suitable to replace injection seeds currently used in atmospheric $\mathrm{CO}_{2}$ detection systems:

- Performance is comparable to semiconductor DFB lasers at $1.57 \mu \mathrm{m}$, enabling the realization of more sensitive instruments at $2.05 \mu \mathrm{m}$

- Robust and compact replacement for current solid-state lasers operating at $2.05 \mu \mathrm{m}$ 
This work was supported by NASA's Earth Science Technology Office under Advanced Component Technology (ACT)

$$
\text { and }
$$

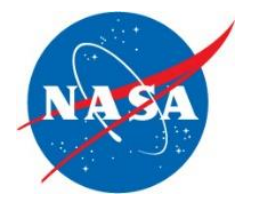

Jet Propulsion Laboratory (JPL) Research and Technology Development (RTD) Program and performed at the Jet Propulsion Lab, California Institute of Technology under contract with NASA

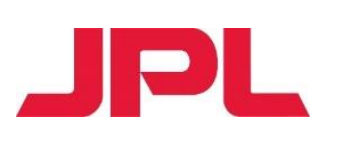

- Laser wafer growth:

- Leon Shterengas and Gregory Belenky, Power Photonic, Inc. (Stony Brook Univ.)

$\star \mathbb{P}$ Stony Brook University

- James Gupta, Canadian National Research Council 